\title{
A PROTEÇÃO INTERNACIONAL DOS DIREITOS HUMANOS E O DIREITO INTERNACIONAL DO MEIO AMBIENTE: CONSIDERAÇÕES INICIAIS
}

\author{
THE INTERNATIONAL PROTECTION OF HUMAN RIGHTS AND THE \\ INTERNATIONAL RIGHT OF THE ENVIRONMENT : INITIAL CONSIDERATIONS
}

Ana Karina Ticianelli Möller"

Tânia Lobo Muniz

\begin{abstract}
Resumo: O presente artigo pretende desenvolver a discussão sobre a relação existente entre a proteção dos direitos humanos e a do meio ambiente, como uma das grandes prioridades da agenda internacional contemporânea.
\end{abstract}

Palavras-chave: Direitos Humanos. Direito Internacional. Meio ambiente.

\begin{abstract}
This present article intends to develop the discussion about the existent relation between the human rights and the environment, as one of the major priorities of the contemporany international agenda.
\end{abstract}

Keywords: Human Rights. International Law. Environment.

\section{INTROUÇÃO}

A proteção internacional dos direitos humanos e o direito internacional do meio ambiente são, dentro do contexto do direito internacional público, os dois grandes temas da globalidade. Apesar dos dois assuntos terem maturidade biológica, as questões inerentes à inter-relação entre os temas ainda não foram devidamente esclarecidas no âmbito das relações internacionais contemporâneas (MAZZUOLI, 2004b, p. 97).

A inserção do tema "meio ambiente" na esfera de proteção dos direitos humanos, notadamente após a Segunda Guerra Mundial, decorreu da percepção de que questões ligadas à sua proteção não se limitam somente à poluição ambiental, mas abrangem um universo social e econômico muito mais amplo.

"Advogada, especialista em Direito Empresarial e mestranda em Direito Negocial pela Universidade Estadual de Londrina.

*** Docente titular do programa de Mestrado em Direito Negocial da Universidade Estadual de Londrina. Doutora em direito pela PUC/SP. 
No que pese a pauta principal ter sido o meio ambiente, a Conferência das Nações Unidas sobre o Meio Ambiente e Desenvolvimento, realizada no Rio de Janeiro, de 3 a 14 de junho de 1992, considerada um marco do Direito Internacional Ambiental, resultou na reafirmação de princípios internacionais de direitos humanos, como os da indivisibilidade e interdependência, conectando-os às regras de proteção ao meio ambiente.

Os diversos estudos sobre as mudanças climáticas sofridas pelo planeta e suas conseqüências, bem como a elaboração de inúmeros tratados internacionais a respeito, demonstram que o assunto é relevante para a humanidade.

O presente estudo pretende relatar essa importância dada aos temas de direitos humanos e meio ambiente em nível internacional, abordando o significado e abrangência dos tratados, especialmente das proposições em foco, e suas repercussões nas sociedades contemporâneas.

\section{BREVES CONSIDERAÇÕES SOBRE TRATADOS INTERNACIONAIS}

Para melhor compreensão dos assuntos a serem tratados é necessário um sucinto relato do significado jurídico de tratados internacionais, por constituírem importante fonte de obrigação do Direito Internacional, com natureza de obrigatoriedade e de vinculação, por meio de análise de sua formação e conseqüências.

A Convenção de Viena sobre o Direito dos Tratados, de 26 de maio de 1969, teve como finalidade codificar as principais regras costumeiras sobre a matéria, disciplinando e regulando o processo de formação dos tratados internacionais. Limitou-se, porém, aos acordos celebrados entre Estados, não abrangendo aqueles dos quais participam organizações internacionais ${ }^{1}$. Posteriormente, esta Convenção foi complementada pela de 1986 sobre o Direito dos Tratados e Organizações Internacionais, cujo objetivo foi precisamente o de regulamentar essa realidade, em relação a estas entidades.

O tratado é uma das principais fontes do direito internacional público, em conjunto com os costumes internacionais e princípios gerais do direito. Indica uma modalidade de ato jurídico, através do qual se manifesta um acordo de vontades entre duas ou mais entidades dotadas de personalidade jurídica

${ }^{1}$ De acordo com Flávia Piovesan, a celebração de tratados entre Estados e organizações internacionais e entre organizações internacionais é cada vez mais freqüente. Este fato alterou a noção tradicional de que o tratado era exclusivamente um acordo entre Estados, pela noção de tratado é acordo entre dois ou mais sujeitos de direito internacional. (PIOVESAN, 2000, p. 66). 
A proteção internacional dos direitos humanos e o Direito Internacional do Meio Ambiente

internacional (ACCIOLY; SILVA, 1996). "É o acordo formal, concluído entre sujeitos de direito internacional público, e destinado a produzir efeitos jurídicos” (REZEK, 1996, p. 112). Ou ainda, "ato jurídico segundo o qual os Estados e Organizações Internacionais que obtiveram personalidade por acordo entre diversos Estados criam, modificam ou extinguem uma relação de direito existente entre eles” (ARAÚJO, 1988, p. 33).

Outras denominações, além de tratado, podem ser utilizadas para se referir a acordos internacionais, tais como convenção, pacto, protocolo, carta, convênio, etc.

Para a sua validade é preciso que haja concurso de vontades, que as partes sejam sujeitos de direito internacional, que crie compromissos jurídicos com caráter obrigatório e deve ser regulado pelo direito internacional. (DINH; DAILLIER, 2003). O consentimento deve ser mútuo e livre, e o objeto lícito e possível.

Por determinação constitucional, os tratados internacionais, entendidos no seu sentido amplo, entram no ordenamento jurídico brasileiro por um processo de transformação denominado internação, internalização, incorporação ou recepção dos tratados internacionais. É um tipo de transformação para que o documento internacional vire um direito interno, com todas as características que a norma possui. Isto porque, no Brasil adota-se um sistema dualista no qual a norma internacional, o tratado internacional in casu, não é aplicada diretamente, necessitando passar por um processo para transformá-lo em norma do ordenamento jurídico interno (ARIOSI, 2004).

De modo geral, o processo de conclusão e internalização podem ser divididos em quatro fases distintas: a negociação, com a discussão dos termos de seu conteúdo, entre os signatários; a assinatura do texto final, avaliado pela equipe negociadora; o referendum, internalização propriamente dita, pelo Congresso Nacional, com a instrumentalização do texto em Decreto Legislativo, e finalmente a fase de ratificação e promulgação, pelo Presidente da República, com a edição do Decreto do Executivo. Após a promulgação e publicação do Decreto do Executivo, este adquire vigência no ordenamento jurídico interno brasileiro com hierarquia de lei federal ordinária.

É diferenciado o procedimento, porém, quando seu conteúdo refere-se a direitos humanos. A Constituição Federal do Brasil, em seu art. 5르, par. $2^{\underline{a}}$, promove a interação entre o Direito Brasileiro e os tratados internacionais de direitos humanos ao dispor que os direitos e garantias e dispondo ali expressos "não excluem outros decorrentes do regime e dos princípios por ela adotados, ou dos tratados internacionais em que a República Federativa do Brasil seja parte”, incluindo, desta maneira, no catálogo dos direitos constitucionalmente protegidos, os direitos enunciados nos tratados firmados pelo Brasil (PIOVESAN, 2000). 
Assim, todos os instrumentos de proteção de direitos humanos ratificados pelo Brasil (tratados internacionais sobre direitos civis e políticos e sobre direitos econômicos, sociais e culturais), passam a deter o "status" de normas constitucionais, incorporando-se automaticamente no ordenamento jurídico brasileiro. (MAZZUOLI, 2004b, p. 121).

O tratamento jurídico diferenciado, segundo Flávia Piovesan,

justifica-se na medida em que os tratados internacionais de direitos humanos apresentam um caráter especial, distinguindo-se dos tratados internacionais comuns. Enquanto estes buscam o equilíbrio e a reciprocidade de relações entre Estados partes, aqueles transcendem os meros compromissos recíprocos entre os Estados pactuantes. Os tratados de direitos humanos objetivam a salvaguarda dos direitos do ser humano e não das prerrogativas do Estado (PIOVESAN, 2000, p. 159-228).

\section{CONSIDERAÇÕES SOBRE A PROTEÇÃO INTERNACIONAL DOS DIREITOS HUMANOS}

O Direito Internacional dos Direitos Humanos tem sua base doutrinária em uma moralidade com padrões mínimos e firma-se num consenso sobre duas proposições morais: todos têm direito a condições mínimas de uma vida digna a ser vivida e certas liberdades e proteções são necessárias para tal vida (FREEMAN, 2002). Consiste em um sistema de normas internacionais, procedimentos e instituições desenvolvidas para implementar esta concepção e promover o respeito dos direitos do homem em âmbito mundial (PIOVESAN, 2000).

Surge em meados do século XX, em decorrência da Segunda Grande Guerra Mundial e, segundo Richard B. Bilder (1992 apud PIOVESAN, 2003), seu movimento é baseado na concepção de que toda nação tem a obrigação de respeitar os direitos humanos de seus cidadãos e de que todas as nações e a comunidade internacional têm o direito e a responsabilidade de protestar, se um Estado não cumprir suas obrigações. Neste contexto, o ser humano passa a ocupar posição central nas sociedades contemporâneas.

A aprovação da Declaração dos Direitos Humanos, adotada e proclamada pela resolução 217 A (III), da Assembléia Geral das Nações Unidas, em 10 de dezembro de 1948, foi o verdadeiro marco divisor do processo de internacionalização dos direitos humanos, ensejando a produção de inúmeros tratados internacionais destinados a proteger todos os indivíduos. Até então, as questões humanitárias estavam restritas a algumas poucas legislações internas de alguns países e somente integravam a agenda internacional na ocorrência de guerras (MAZZUOLI, 2004b, p. 100). 
A proteção internacional dos direitos humanos e o Direito Internacional do Meio Ambiente

A dignidade inerente a todos os seres humanos independentemente da sua nacionalidade é o eixo filosófico da Declaração dos Direitos do Homem, que é universal por sua expressão, por seu conteúdo, por seu campo de aplicação e dá início a uma fase da humanidade na qual a afirmação dos direitos humanos é ao mesmo tempo universal e positiva (GREGORI, 2002). Esse ponto de vista tornou possível o surgimento de inúmeros acordos internacionais protetivos dos direitos humanos, tanto em aspectos civis e políticos, como relativos às áreas de domínio econômico, social e cultural, tanto mundial como regional e todo um sistema internacional de sua proteção.

A concepção contemporânea de direitos humanos, introduzida pela Declaração, conjuga o valor da liberdade com o valor da igualdade, e dá ênfase à universalidade, indivisibilidade e interdependência dos direitos humanos, reafirmados posteriormente na Declaração de Viena de 1993, em seu artigo 5ª , que dispõe que os direitos humanos são universais, interdependentes e inter-relacionados, definitivamente legitimando a noção de indivisibilidade desses direitos, cujos preceitos devem ser aplicados tanto aos direitos civis e políticos, como aos econômicos, sociais e culturais, e enfatizando os direitos de solidariedade, o direito à paz, o direito ao desenvolvimento e os direitos ambientais.

A criação desses sistemas normativos, tanto na esfera global pela Organização das Nações Unidas, como nas esferas regionais, elevou o ser humano à categoria de sujeito de direito internacional público, preservando o indivíduo de ações danosas, inclusive do próprio Estado, e por meio desses instrumentos gerais e regionais, e também especiais, que visam determinados sujeitos de direito, busca a preservação do indivíduo de ações danosas, inclusive do próprio Estado.

Nesse sentido, como diz o pensador italiano Norberto Bobbio, de que a "Declaração Universal representa a consciência histórica que a humanidade tem dos próprios valores fundamentais, na segunda metade do século XX. É uma síntese do passado e uma inspiração para o futuro: mas suas tábuas não foram gravadas para sempre" (BOBBIO, 1992, p. 34), e considerando então, que os direitos humanos não são um dado, mas um construído, uma invenção humana em constante processo de construção e reconstrução (ARENDT, 1979, apud PIOVESAN, 2005), aliado ao desenvolvimento progressivo do Direito internacional dos Direitos Humanos, no contexto das relações internacionais contemporâneas, foram introduzidos inúmeros tratados de proteção ao meio ambiente. 


\section{DO DIREITO INTERNACIONAL DO MEIO AMBIENTE}

\subsection{A tomada de consciência}

Uma das realidades do Século XX, trazida para o Século XXI, é a necessidade de proteção do meio ambiente, em razão dos problemas surgidos em função das intensas atividades industriais e de um consumismo humano exacerbado em nível mundial, com desenvolvimento a qualquer custo, resultando em um desequilíbrio entre o meio ambiente e a atividade econômica.

$\mathrm{O}$ processo de globalização das economias nacionais e a gravidade dos problemas globais, somente enfrentáveis por meio de esforço mundial, introduzem na história humana a necessidade de se aprofundar a definição e a consolidação jurídica do conceito de interesse público internacional, para protegê-lo da forma mais efetiva possível, como a maior das prioridades.

Houve, durante os séculos passados, preocupações isoladas, com a água, preservação de determinados animais e conservação da paisagem construída pelo homem, mas sem a consciência de que a proteção destes fatores transcende ao nível local, pois a percepção de que se encontram entrelaçados numa rede de inter-relações entre os próprios fatores e entre espaços nacionais e extras nacionais, é fenômeno atual (SOARES, 2002).

Essa compreensão começa a acontecer quando a poluição passa a ser considerada um evento que ultrapassa as fronteiras, e que os planos de preservação do meio ambiente e antipoluição somente alcançariam resultados efetivos caso houvesse uma ação em escala mundial.

\subsection{Os marcos legais}

O Direito Ambiental passa a ter mais em evidência na década de 70 do Século XX, com a realização da Conferência das Nações Unidas para o Ambiente Humano, em 1972, em Estocolmo, na Suécia. Nesta Conferência foi proclamado que a forma ideal de planejamento ambiental é aquela que associa a prudência ecológica às ações pró-desenvolvimento, o eco desenvolvimento.

Foi, então, dado início a uma conscientização ecológica, aliada à necessidade de cooperação internacional para a proteção do meio ambiente. Os Estados e organizações não governamentais foram encorajados a efetivar medidas de proteção ambiental e houve uma sensibilização da opinião pública sobre o assunto e a urgência das questões debatidas.

Nesse encontro, restou destacada a preocupação especial com o meio ambiente, consagrando, solenemente, princípios basilares na Declaração sobre o Ambiente Humano ${ }^{2}$ : 
A proteção internacional dos direitos humanos e o Direito Internacional do Meio Ambiente

Princípio 1: $\mathrm{O}$ homem tem o direito fundamental à liberdade, à igualdade e ao desfrute de condições de vida adequadas, em um meio ambiente de qualidade tal que lhe permita levar uma vida digna e gozar de bem estar e é portador solene de obrigação de proteger e melhorar o meio ambiente, para as gerações presentes e futuras. A esse respeito, as políticas que promovem ou perpetuam o apartheid, a segregação racial, a discriminação, a opressão colonial e outras formas de opressão e de dominação estrangeira permanecem condenadas e devem ser eliminadas.

Princípio 2: Os recursos naturais da Terra, incluídos o ar, a água, o solo, a flora e a fauna, e especialmente, parcelas representativas dos ecossistemas naturais, devem ser preservados em beneficio das gerações atuais e futuras, mediante uma cuidadosa planificação ou regulamentação, segundo seja mais conveniente.

Princípio 3: Deve ser mantida, e sempre que possível restaurada e melhorada a capacidade da Terra de produzir recursos vitais renováveis Princípio 4: $\mathrm{O}$ homem tem a responsabilidade especial de preservar e administrar ponderadamente o patrimônio representado pela flora e fauna silvestre, bem assim o seu habitat, que se encontram atualmente em grave perigo, em virtude da conjugação de diversos fatores. "Conseqüentemente, ao se planejar o desenvolvimento econômico, deve atribuir-se uma importância específica à conservação da natureza” (DECLARAÇÃO..., 1972).

Vinte anos depois, em 1992, foi realizada no Rio de Janeiro, a maior conferência mundial sobre problemas ambientais, a Conferência das Nações Unidas sobre Ambiente e Desenvolvimento (CNUMAD), que ficou conhecida como ECO 92. O objetivo era elaborar estratégias e medidas para deter a degradação ambiental, no Brasil e no mundo, promovendo o desenvolvimento sustentável.

A ECO 92 mostrou que os padrões de produção e consumo estavam em níveis insustentáveis e que ajudar os países em desenvolvimento, por meio de cooperação técnica e científica, bem como apoio financeiro, poderia ajudar a abaixar os índices de degradação ambiental.

O direito soberano dos Estados sobre seus recursos naturais foi ressaltado, porém estes têm o dever e a responsabilidade de evitar qualquer tipo de dano ambiental, respeitando os Estados vizinhos, protegendo a geração presente e a futura, lutando contra a pobreza e investindo no desenvolvimento.

$\mathrm{Na}$ ECO 92 foram traçados os princípios éticos da equidade e de tomada de decisão, que se tornaram freqüentes nas negociações ambientais e que foram adotados posteriormente na Convenção Quadro ${ }^{3}$ das Nações Unidas sobre a Mudança do Clima, de 1992 e, conseqüentemente, no Protocolo de Quioto, de 11 de dezembro de 1997, como será visto a seguir.

${ }^{2}$ Declaração firmada por ocasião da Conferência das Nações Unidas, em Estocolmo, Suécia, de 05 a 15 de junho de 1972. 
Surgiu, também, a necessidade de regulamentação das questões ambientais, uma vez que somente a preocupação com o meio ambiente não conseguiria frear o desenvolvimento industrial com degradação ambiental, com conseqüentes à saúde humana e animal. A preocupação e a necessidade de regulamentação atingiram a comunidade internacional.

A Convenção Quadro das Nações Unidas sobre Mudança de Clima foi aberta para assinatura e ratificação na Conferência Mundial sobre Problemas Ambientais (CNUMAD), e concluída em 09 de maio de 1992. Entrou em vigor em 21 de março de 1994, com 189 Países-partes firmando seus termos. Teve como objetivo estabilizar a emissão de gases de efeito estufa de modo a prevenir a intervenção humana maléfica para a atmosfera.

Por meio desta Convenção, a Organização das Nações Unidas (ONU) reconheceu que as mudanças climáticas devem ser vistas como um problema da humanidade, de vital importância para as gerações presentes e futuras. Assim, foram estabelecidas regras gerais sobre a emissão de gases que causam o efeito estufa, em especial o dióxido de carbono. ${ }^{4}$

Os Estados-partes são divididos em dois grupos, em virtude das diferenças econômicas, sociais e de nível de desenvolvimento: o Anexo I ${ }^{5}$ e o Não Anexo I. O primeiro contém os Estados desenvolvidos, industrializados e ricos e também os industrializados em processo de transição para uma economia de mercado ${ }^{6}$. No segundo estão 189 Estados considerados ainda em desenvolvimento, entre eles o Brasil.

${ }^{3}$ Convenção-Quadro é um tipo de convenção que necessita de outros meios para regulamentá-la, não é considerada um tratado impositivo, com normas e regras cogentes, não implica sanções aos que a descumprirem, é uma soft law. Trata de muitos assuntos ao mesmo tempo, sem ênfase especial a nenhum deles. De acordo com Guido Fernandes Silva Soares, alguns autores entendem que a soft law exprime apenas uma obrigação moral ou natural ligada à idéia de equidade. Embora não existam acordos doutrinários claros sobre a abrangência conceitual desta expressão, esta é uma fonte de direito internacional utilizada em sentido genérico para acordos, protocolos, declarações de princípios, entre outros (SOARES, 2002).

${ }^{4}$ Gás ligeiramente tóxico, inodoro, incolor e de sabor ácido, obtido como subproduto de algumas combustões.

${ }^{5} \mathrm{Na}$ Convenção, o chamado Anexo I é o bloco de países que possuem metas obrigatórias de redução, sendo composto essencialmente por países do oeste europeu, Japão e Canadá.

${ }^{6}$ Belarus, Bulgária, Croácia, Eslovênia, Estônia, federação Russa, Hungria, Letônia, Lituânia, Polônia, República Tcheca, República Eslovaca, Romênia e Ucrânia. 
A proteção internacional dos direitos humanos e o Direito Internacional do Meio Ambiente

Com a idéia e o reconhecimento de que os Estados desenvolvidos, como os da União Européia ${ }^{7}$ e os Estados Unidos da América do Norte, foram os maiores responsáveis pela poluição do ar no último século, estes países foram convocados a arcar com a conseqüência de seus atos.

A responsabilização diferenciada, que resultou no estabelecimento de metas de estabilização dos níveis de emissão de gases de efeito estufa apenas para os Estados desenvolvidos, é baseada no principio de responsabilidade comum, porém diferenciada, adotada pela Convenção Quadro das Nações Unidas sobre Mudanças de Clima, e que rege usualmente as relações entre os países desenvolvidos e os países em desenvolvimento, constituindo exceção ao principio da reciprocidade das partes (FRANGETTO; GAZANI, 2002).

O princípio de responsabilidade comum, porém diferenciada está previsto no Art. 3 da Convenção Quadro e afirma que devem ser consideradas as necessidades específicas e as circunstâncias especiais dos Estados-partes considerados em desenvolvimento, e que a iniciativa de ações de combate à mudança do clima e seus efeitos advenha dos países desenvolvidos (YOSHIDA, 2006).

Criou-se o princípio poluidor pagador, recurso econômico utilizado para que o poluidor arque com os custos da atividade poluidora, que confirma que os citados Estados desenvolvidos são os maiores causadores e responsáveis pelo efeito estufa no Planeta Terra, sendo de sua responsabilidade tomar medidas para combater os desgastes ambientais. De acordo com Antônio Herman Benjamin, o princípio poluidor-pagador não é um princípio de compensação dos danos causados pela poluição, pois seu alcance "é mais amplo, incluídos todos os custos da proteção ambiental, quaisquer que eles sejam, abarcando, a nosso ver, os custos da prevenção, de reparação e de repressão do dano ambiental..." (BENJAMIN, 1993, p. 227).

A Convenção Quadro das Nações Unidas sobre Mudança do Clima prevê ajuda científica e financeira para os países em desenvolvimento e pode contar com a participação e apoio de Organizações Internacionais que tenham interesse,

${ }^{7}$ Bloco econômico, político e social, que em 2007 alcançou a marca de 27 países e quase meio bilhão de pessoas que participam de um projeto de integração política e econômica. Os países integrantes são: Alemanha, Áustria, Bélgica, Bulgária, Chipre, Dinamarca, Eslováquia, Eslovênia, Espanha, Estonia, Finlândia, França, Grécia, Hungria, Irlanda, Itália, Letônia, Lituânia, Luxemburgo, Malta, Países Baixos, Polônia, Portugal, Reino Unido, Romênia, República Checa e Suécia. (ESTADOS-MEMBROS da União Européia. Disponível em: <http://europa.eu/abc/governments/ index_pt.htm>. Acesso em: 18 abr. 2007). 
por meio de assistência financeira, suporte técnico e ajuda para construir mecanismos que sejam viáveis ecologicamente.

O Protocolo de Quioto surge como um anexo à Convenção, com a função de regulamentá-la e especifica-la, com regras próprias e sanções aos infratores, fazendo com que o documento ganhe em eficácia e efetividade. É um acordo internacional patrocinado pela ONU, firmado em 1997, por 59 países, na cidade de Quioto, no Japão.

Esse Tratado tem por objetivo reduzir as emissões de gases de efeito estufa GEEs em nações industrializadas, através de metas que correspondem, em média, à redução de 5,2\% sobre o montante de gases emitidos pelo país signatário do Protocolo em 1990 e estabelecer modelo de desenvolvimento limpo para os países emergentes, como será explicado adiante.

O Protocolo entrou em vigor em 16 de fevereiro de 2005, 90 dias após a Rússia ter formalizado sua adesão. A ratificação russa cumpriu o requisito essencial para sua vigência, ou seja, a ratificação por 55 Estados-partes que respondam por pelo menos 55\% das emissões globais de gases de efeito estufa. Quando isto ocorreu, o Protocolo contava com adesão de 141 países, correspondendo a 61,6\% das emissões globais.

Os países desenvolvidos, listados no Anexo $\mathrm{B}^{8}$ do Protocolo de Quioto, devem cumprir suas metas de redução de emissões de gases de efeito estufa no decorrer do chamado primeiro período de compromisso, que corresponde aos anos de 2008 a 2012. Para o segundo período, após 2012, foi realizada a Conferência de Montreal, no Canadá, de 28 de novembro a 10 de dezembro de 2005, onde os países que aderiram ao Protocolo de Quioto concordaram em começar a discutir o que será nessa etapa, porém sem estabelecer prazos.

Os objetivos do Protocolo são a redução da emissão de gases de efeito estufa e a sua maior absorção pelos sumidouros naturais ${ }^{9}$. As medidas vinculantes e

\footnotetext{
${ }_{8}^{8}$ Alemanha, Austrália, Áustria, Bélgica, Bulgária, Canadá, Comunidade Européia, Croácia, Dinamarca, Eslováquia, Eslovênia, Espanha, Estados Unidos da América, Estônia, Federação Russa, Finlândia, França, Grécia, Hungria, Irlanda, Islândia, Itália, Japão, Letônia, Liechtenstein, Lituânia, Luxemburgo, Mônaco, Noruega, Nova Zelândia, Paises Baixos, Polônia, Portugal, Reino Unido da Grã-Bretanha e Irlanda do Norte, República Tcheca, Romênia, Suécia, Suíça e Ucrânia.

${ }^{9}$ De acordo com a Convenção Quadro das Nações Unidas sobre Mudança do Clima, sumidouros naturais são quaisquer processos, atividades ou mecanismos, incluindo a biomassa, e, em especial, florestas e oceanos, que têm a propriedade de remover um gás de efeito estudo, aerossóis ou precursores de gases de efeito estufa da atmosfera. Podem constituir-se também de outros ecossistemas terrestres, costeiros e marinhos.
} 
A proteção internacional dos direitos humanos e o Direito Internacional do Meio Ambiente

flexibilizadoras atuam no duplo sentido de pressionar pelo cumprimento das metas e incentivar a adoção de meios mais práticos e baratos de cumpri-las. Define, ainda, metas individuais para cada Estado e vincula cumprimento destas normas com medidas sancionatórias.

Porém, a criação de princípios e orientações de conduta foi reconhecida como não suficiente para que a redução de emissão de gases de efeito estufa se tornasse efetiva, necessitando de medidas concretas e sanções aplicáveis para o alcance das metas propostas.

Foram, então, programadas, em decorrência dos objetivos comuns de poluição definidos, sanções aplicáveis em caso de descumprimento, tendo em vista a dificuldade em estabelecer o elo entre o Estado poluidor e a poluição. O Sistema de Cumprimento das regras impostas pelo Protocolo foi de fundamental importância, uma vez que não existiam sanções jurídicas, até então, pelo descumprimento pelas Partes.

\subsection{Sistemas de atuação}

Os Tratados acima criaram um sistema de ajuda para os Estados em desenvolvimento que não possuem condições e meios necessários para implementar as normas do Protocolo, com dois mecanismos. O primeiro trata sobre assistência técnica e financeira, transferência de tecnologia, treinamento e educação. O segundo mecanismo é sobre a ajuda na diminuição dos custos da redução da emissão de carbono na atmosfera.

São elaborados relatórios anuais das Partes e inventário de emissão de gases estufa para verificar se estão sendo mantidos regularmente os compromissos firmados. A verificação destes relatórios traz a perspectiva de andamento da implementação dos mecanismos internos que estão sendo adotados pelos diversos signatários.

O Protocolo de Quioto regulamenta arranjos técnico-operacionais para utilização por parte de empresas ou países, que oferecem facilidades para que os Estados constantes no Anexo B do Protocolo possam atingir limites e metas de redução de emissões. Tais instrumentos também têm o propósito de incentivar os países emergentes a alcançar um modelo adequado de desenvolvimento sustentado.

Para auxiliar os signatários, o Protocolo de Quioto dispõe de mecanismos de flexibilização, de acordo com a realidade individual particular, se industrializado, se em transição para economia de mercado, ou se em desenvolvimento. São três os mecanismos de flexibilização previstos, quais sejam: Comércio de Emissões Emission Trading, realizado entre Estados listados no Anexo B, de maneira que aquele que tenha diminuído suas emissões para abaixo de sua meta, transfira o excesso de suas reduções para outro que não tenha alcançado tal condição; 
Implementação Conjunta - Join Implemantation, implantação de projetos de redução de emissões de GEEs em países que apresentam metas no âmbito do protocolo e finalmente, Mecanismo de Desenvolvimento Limpo - Clean Development Mechanism, que será visto a seguir.

A idéia de Mecanismo de Desenvolvimento Limpo (MDL) - pode ser resumida na constatação de que a redução de uma unidade de GEEs emitida na atmosfera voluntariamente por uma empresa situada em um país em desenvolvimento poderá ser negociada no mercado mundial com os países industrializados (ou empresas nele situadas) que precisam desses créditos para cumprir suas metas em conformidade ao Protocolo de Quioto.

Para a validade de um projeto de MDL, é preciso que este realize o desenvolvimento sustentável no Estado que o esteja recebendo, devendo observar os seguintes requisitos: participação voluntária aprovada por cada parte envolvida, benefícios reais, mensuráveis e de longo prazo, relacionados com a mitigação da mudança do clima; e reduções de emissões que sejam adicionais as que ocorreriam na ausência da atividade certificada do projeto (FRANGETTO; GAZANI, 2002).

Assim, torna-se possível reduzir as emissões globais de gases de efeito estufa e, ao mesmo tempo, abre-se importante alternativa para o desenvolvimento sustentável dos países em desenvolvimento.

\subsection{Desenvolvimento sustentável}

O conceito de desenvolvimento sustentável foi introduzido no âmbito do direito internacional, em 1992, na Conferência das Nações Unidas sobre o Meio Ambiente e Desenvolvimento, realizada no Rio de Janeiro, que o fez constar em vários dos princípios contidos na "Declaração do Rio de Janeiro sobre Meio Ambiente e Desenvolvimento", reforçando a idéia de que o desenvolvimento e a preservação do meio ambiente são possíveis ao mesmo tempo.

Segundo relatório da Comissão Mundial sobre Meio Ambiente da ONU, "é sustentável o desenvolvimento tal que permite satisfazer nossas necessidades atuais sem comprometer a capacidade das gerações futuras de satisfazer as suas" ${ }^{\prime 1}$.

${ }_{10}$ Publicado em abril de 1987, o Relatório "Nosso Futuro Comum”, é um estudo preparado na Comissão Mundial sobre Meio Ambiente e Desenvolvimento da ONU. O relatório, publicado no Brasil pela Fundação Getúlio Vargas, gerou a Eco-92, realizada no Rio de Janeiro, cinco anos depois. Este relatório inaugurou o conceito de "desenvolvimento sustentável" e prevê exatamente o que o Painel Intergovernamental sobre Mudanças Climáticas (IPCC) alertou recentemente sobre desastres ambientais. 
A proteção internacional dos direitos humanos e o Direito Internacional do Meio Ambiente

Nesse sentido, a idéia de um desenvolvimento sustentável diz respeito à exploração de recursos naturais no presente sem comprometer os recursos naturais à disposição das gerações futuras (DERANI, 2001), o que implica na necessidade de conciliação entre os interesses econômicos e a preservação do meio ambiente.

No entanto, o conceito de desenvolvimento sustentável envolve outras facetas. Uma delas é o aspecto social, daí o termo "desenvolvimento", que aponta para a necessidade de superação da pobreza e exclusão nos países em desenvolvimento, num cenário de degradação ambiental.

Nesse contexto, a idéia de sustentabilidade, relaciona-se à preservação e valorização da diversidade étnica e cultural e estimula formas diferenciadas de utilização de biodiversidade e dos recursos naturais (COUTINHO, 2004).

A discussão acerca do conceito de desenvolvimento sustentável aponta para a necessidade de sua operacionalização a partir de mecanismos e instrumentos de políticas públicas e de normas jurídicas que definam deveres de preservação ambiental e incentivos para o desenvolvimento de padrões de produção sustentáveis.

Para tanto, discussões a partir de temas concretos de possibilidades de desenvolvimento econômico e necessidade de preservação ambiental são muito importantes, além da necessidade de implementação de técnicas de exploração ambientalmente sadias, ou ao menos de menor danosidade em comparação com os paradigmas predominantes (NUSDEO, 2001).

$\mathrm{O}$ direito soberano dos Estados sobre seus recursos naturais deve ser respeitado, porém estes têm o dever e a responsabilidade de evitar qualquer tipo de dano ambiental, respeitando os soberanos vizinhos, protegendo a geração presente e a futura, lutando contra a pobreza e investindo no desenvolvimento.

Aliadas às discussões ambientais, existem questões sociais, pois não há como separar a preocupação com o meio ambiente do aspecto social. Ações dirigidas a um destes temas refletem diretamente no outro, tendo em vista que o desequilíbrio do meio ambiente acarreta inúmeros prejuízos à sociedade, assim como o desequilíbrio das sociedades causa danos ambientais.

Nessa perspectiva, atuações visando o desenvolvimento sustentável, por meio do equilíbrio entre proteção ambiental, inserção social e crescimento econômico, ganham cada vez mais força nas sociedades contemporâneas.

O documento ficou conhecido como relatório Brundtland, já que a Comissão era presidida por Gro Harlem Brundtland, então primeira-ministra da Noruega. (Disponível em: http://www.ana.gov.br/acoesadministrativas/relatoriogestao/rio10/riomaisdez). 


\section{O DIREITO AO MEIO AMBIENTE EQUILIBRADO COMO UM DIREITO HUMANO FUNDAMENTAL}

Se por muito tempo o meio ambiente foi visto como algo dissociado dos direitos humanos, a partir do Século XX, com o aumento significativo das tragédias ambientais, ele passou a ser reconhecido como um valor autônomo no meio jurídico, acabando com a visão utilitarista das normas ambientais antigas, para passar a considerar a proteção ao meio ambiente um direito de todos.

Como destaca Guido Fernando da Silva Soares, as normas de proteção ao meio ambiente "têm sido consideradas como um complemento aos direitos do homem, em particular o direito á vida e à saúde humana” (SOARES, 2003, p. 173).

Finda a Segunda Guerra Mundial, essa preocupação torna-se questão de natureza internacional, ao inserir o tema no art. 12 do Pacto Internacional de Direitos Econômicos, Sociais e Culturais, de 1966, ao dispor sobre o direito a um nível de vida adequado. No que pese a referência ter sido indireta, ficou reconhecido que o direito ao uma vida digna está intrinsicamente ligado a um meio ambiente sadio e equilibrado. Para Cançado Trindade, "parecia aberto o caminho para o reconhecimento futuro do direito a um meio ambiente sadio" (CANÇADO TRINDADE, 1993, p. 84).

$\mathrm{O}$ direito fundamental à preservação do meio ambiente e o direito à vida, foi reconhecido pela Declaração do Meio Ambiente, adotada na Conferência das Nações Unidas, em Estocolmo, em 1972, que assegurou a "correlação de dois direitos fundamentais do homem: o direito ao desenvolvimento e o direito a uma vida saudável” (SILVA, 2000, p. 41). Ficou declarado que o ser humano tem direito fundamental à liberdade, à igualdade e a uma vida com condições adequadas de sobrevivência, num meio ambiente que permita usufruir de uma vida digna, ou seja, com qualidade de vida, com a finalidade também, de preservar e melhorar o meio ambiente, para as gerações atuais e futuras ${ }^{11}$.

O direito a uma ordem nacional e internacional, em que os direitos e liberdades estabelecidos na Declaração Universal possam ser plenamente realizados, passa a ser integrado pelo direito internacional do meio ambiente. É com a garantia de um

\footnotetext{
11 "Princípio 1 - O homem tem o direito fundamental à liberdade, à igualdade e ao desfrute de condições de vida adequada em um meio ambiente de qualidade tal que lhe permita levar uma vida digna, gozar de bem-estar e é portador solene de obrigação de melhorar o meio ambiente, para as gerações presentes e futuras [...]." "Princípio 2 - Os recursos naturais da Terra, incluídos o ar, a água, o solo, a flora e a fauna, especialmente, parcelas representativas dos ecossistemas naturais, devem ser preservadas em benefício de gerações atuais e futuras [...].”
} 
A proteção internacional dos direitos humanos e o Direito Internacional do Meio Ambiente

ambiente ecologicamente equilibrado que os direitos e liberdades estabelecidos na Declaração de 1948 podem ser plenamente realizados (MAZZUOLI, 2004b).

O meio ambiente, passou, portanto, a ser considerado essencial para que o ser humano possa gozar dos direitos humanos fundamentais, dentre eles, o próprio direito à vida.

Nesse sentido, no âmbito da América, o Protocolo Adicional à Convenção Interamericana sobre Direitos Humanos em Matéria de Direitos Econômicos, Sociais e Culturais, conhecido como Protocolo de San Salvador, de 1988, assegura em seu art. 11 o direito a um meio ambiente sadio, dispondo que "toda pessoa tem direito a viver em meio ambiente sadio e a contar com os serviços públicos básicos”, e que "os Estados-partes promoverão a proteção, preservação e melhoramento do meio ambiente."

A inter-relação dos direitos humanos com a proteção internacional do meio ambiente, no atual contexto das relações internacionais, encontra-se em diversos instrumentos internacionais, entre outros (MAZZUOLI, 2004b, p. 113):

1. Convenção sobre Acesso à Informação, Participação Pública e Acesso à Justiça nas Questões Ambientais, conhecida como Convenção de Aarhus, de 25 de junho de 1988, que declara que "toda pessoa tem o direito de viver num ambiente adequado á sua saúde e bem-estar e o dever, tanto individualmente quanto em associação com outros, de proteger e melhorar o meio ambiente em beneficio da geração atual e das gerações futuras”;

2. Convenção das Nações Unidas sobre os Direitos da Criança, de 20 de novembro de 1989, ao dispor que os Estados-partes adotarão medidas apropriadas com vistas a "combater as doenças e a desnutrição, dentro do contexto dos cuidados básicos de saúde mediante, inter-alia, a aplicação de tecnologia disponível e o fornecimento de alimentos nutritivos e água potável, tendo em vista os perigos e riscos da poluição ambiental”;

3. Carta Africana dos Direitos Humanos e dos Povos, de 21 de outubro de 1986, conhecida como Carta de Banjul, que inclui várias disposições relacionadas com o direito ao meio ambiente sadio;

4. Carta dos Direitos Fundamentais da União Européia, de dezembro de 2.000, que dispõe em seu art. 27: "Todas as políticas da União devem integrar um elevado nível de proteção do ambiente e a melhoria de sua qualidade, e asseguralos de acordo com o princípio do desenvolvimento sustentável”.

No Brasil, a previsão constitucional pátria atual sobre o tema é m marco histórico de inegável valor, dado que as Constituições que precederam a de 1988 jamais se preocuparam da proteção do meio ambiente de forma especifica e global. Nelas sequer uma vez foi empregada a expressão "meio ambiente", a 
Ana Karina Ticianelli Möller; Tânia Lobo Muniz

revelar total despreocupação com o próprio espaço em que vivemos (MILARÉ, 1991).

A Constituição de 1988 dispõe que além de um direito, o meio ambiente sadio e equilibrado é um bem de natureza pública, tendo o Poder Público e a coletividade a obrigação, o dever de assegurar a efetividade deste direito, por ser um bem de uso comum do povo, com caráter indisponível, não pertencendo a um ou outro, mas a todos.

A vida tutelada pela Constituição transcende os estreitos limites de sua atuação física, abrangendo também o direito à qualidade de vida sadia em todas as suas formas. Assim, como um direito universalmente reconhecido como um direito humano básico ou fundamental, o seu gozo é condição sine qua non para o gozo de todos os demais direitos humanos, incluído o direito ao meio ambiente equilibrado (CANÇADO TRINDADE, 1993).

\section{CONCLUSÃO}

Por muito tempo o meio ambiente foi visto como lago dissociado da humanidade. Conceito revisto, felizmente e obrigatoriamente, devido aos efeitos sofridos pela população mundial nas últimas décadas. No que pese a mudança conceitual, não basta conscientização sem que haja ação.

Ao se constatar que os efeitos ambientais são transfronteiriços, torna-se ainda maior a responsabilidade global no empenho em proporcionar qualidade de vida e ambiente sadio, a toda a população mundial.

A proteção internacional do meio ambiente não é, nem deve ser matéria de domínio exclusivo da legislação interna dos Estados. É um dever de toda a comunidade internacional e deve ser visto como uma conquista da humanidade.

A inserção da temática ambiental na esfera dos direitos humanos por meio dos tratados internacionais é um grande avanço, que abrange um universo muito mais complexo do que simplesmente questões relativas à poluição ambiental. Há a consciência de que ambiente em desequilíbrio é uma forte ameaça à saúde e a economia mundial.

Os efeitos conhecidos devidos às mudanças ambientais não foram provocados em pouco tempo e tampouco serão amenizados rapidamente. Serão necessárias medidas drásticas, sem, no entanto, prejudicar a economia dos Estados, bem como o mercado internacional.

O conceito de desenvolvimento sustentável requer bom senso e razoabilidade, uma vez que deve aliar proteção e desenvolvimento, garantindo qualidade e meios dignos de vida, a presente e futuras gerações. 
A proteção internacional dos direitos humanos e o Direito Internacional do Meio Ambiente

As ações voltadas ao desenvolvimento sustentável devem ser vistas como obrigação dos Estados e não como caridade ou generosidade. Ainda que existam limitações de ordem econômica, tecnológica, e outras, para implementação de atividades que visam produção aliadas ao respeito ao ser humano, na busca de desenvolvimento, os Estados tem o dever de buscar alternativas visando o bem comum, considerando o direito ao meio ambiente como parte integrante e indissolúvel dos direitos humanos de todas as nações.

O respeito ao meio ambiente é respeito ao ser humano. Justiça e oportunidade de vida digna a todos e não apenas a alguns privilegiados, sem destruição dos recursos naturais finitos e sem colocar em dúvida a sustentabilidade da Terra.

\section{REFERÊNCIAS}

ACCIOLY, Hildebrando; SILVA, Geraldo Eulálio do Nascimento. Manual de Direito Internacional Público. São Paulo: Saraiva, 1996.

ARAÚJO, Luis Ivani de Amorim. Curso de Direito Internacional Público. 9. ed. Rio de Janeiro: Forense, 1988.

ARIOSI, Mariângela F. O iter procedimental da recepção dos tratados internacionais no ordenamento jurídico brasileiro. Jus Navigandi, Teresina, ano 9, n. 498, 17 nov. 2004. Disponível em: <http://jus2.uol.com.br/doutrina/ texto.asp?id=5943>. Acesso em: 24 maio 2007.

BENJAMIN, Antônio Herman V. O princípio poluidor-pagador e a reparação do dano ambiental. In: BENJAMIN, Antônio Herman V. (Coord.). Dano ambiental: prevenção, reparação e repressão. São Paulo: Ed. RT, 1993.

BOBBIO, Norberto. A Era dos Direitos. 10 ed. Rio de Janeiro: Campus, 1992.

CANÇADO TRINDADE, Antônio Augusto. Direitos Humanos e Meio Ambientes: paralelo dos sistemas de proteção internacional. Porto Alegre: Fabris, 1993.

. O Direito Internacional em um Mundo em Transformação (ensaios, 1976-2001). Rio de Janeiro: Renovar, 2002.

COUTINHO, Sonia Maria V. Produção e Consumo Sustentável na Agenda 21. Revista de Direitos Difusos. Adcoa/Ibap, ano 5, v. 24, p. 3369-3378, mar./abr. 2004.

DECLARAÇÃO sobre o Ambiente Humano. Disponível em: <http:// www.ufpa.br/npadc/gpeea/DocsEA/DeclaraAmbientehumano.pdf>. Acesso em: 1 maio 2007.

DERANI, Cristiane. Direito Ambiental Econômico. 2. ed. São Paulo: Max Limonad, 2001. 
Ana Karina Ticianelli Möller; Tânia Lobo Muniz

DINH, Nguyon, Quoc; DAILLIER, Patrick, Alan. Direito Internacional Público. Tradução: Vítor Marques Coelho. Lisboa: Fundação Galouste Gulbenkian, 2003.

ESTADOS-MEMBROS da União Européia. Disponível em: <http://europa.eu/ abc/governments/index_pt.htm>. Acesso em: 18 abr. 2007.

FRANGETTO, Flavia W; GAZANI, Flavio R. Viabilização jurídica do mecanismo de desenvolvimento limpo no Brasil. OProtocolo de Quioto e a Cooperação Internacional.São Paulo: Fundação Peirópolis, 2002.

FREEMAN, Michael. Direitos Humanos no Século XXI - Parte I. Organização: Paulo Sérgio Pinheiro e Samuel Pinheiro Guimarães. Brasília: Instituto de Pesquisa de Relações Internacionais Fundação Alexandre Gusmão/Senado, 2002.

FREITAS, Vladimir Passos de. A constituição federal e a efetividade das normas ambientais. 2. ed. São Paulo: Revista dos Tribunais, 2002.

GREGORI, José. Direitos Humanos no Século XXI - Parte I. Organização: Paulo Sérgio Pinheiro e Samuel Pinheiro Guimarães. Brasília: Instituto de Pesquisa de Relações Internacionais Fundação Alexandre Gusmão/Senado, 2002.

MAZZUOLI, Valério de Oliveira. Tratados Internacionais: com comentários à Convenção de Viena de 1969. São Paulo: Juarez de Oliveira, 2004a.

. A proteção internacional dos direitos humanos e o Direito internacional do meio ambiente. Revista de Direito Ambiental, São Paulo, v. 9, n..34, p. 97-123, abr./jun. 2004b.

MENDEZ, Juan E. Direitos Humanos no Século XXI - Parte I. Organização: Paulo Sérgio Pinheiro e Samuel Pinheiro Guimarães. Brasília: Instituto de Pesquisa de Relações Internacionais Fundação Alexandre Gusmão/Senado, 2002.

MILARÉ, Edis. Legislação ambiental do Brasil. São Paulo: APMP, 1991.

MORAES, Luís Carlos Silva de. Curso de direito ambiental. São Paulo: Jurídico Atlas, 2001.

NUSDEO, Ana Maria de Oliveira. O tratamento internacional do problema da mudança climática, uma análise do protocolo de Quioto. In: DERANI, Cristiane; COSTA, José Augusto F. (Org.). Direito ambiental internacional. São Paulo: Ed. Universitária Leopoldianum, 2001.

PIOVESAN, Flávia. Direitos humanos e o direito constitucional internacional. 4. ed. São Paulo: Max Limonad, 2000. 
A proteção internacional dos direitos humanos e o Direito Internacional do Meio Ambiente

Temas de direitos humanos. 2. ed. rev., ampl. e atual. São Paulo: Max Limonad, 2003.

Ações afirmativas das perspectivas dos Direitos Humanos. Cadernos de Pesquisa, São Paulo, v. 35, n. 124, p. 43-55, jan./abr. 2005.

REZEK, José Francisco. Direito Internacional Público. 6.ed. São Paulo: Saraiva 1996.

SILVA, José Afonso da. Direito ambiental constitucional. 3. ed. São Paulo: Malheiros, 2000.

SOARES, Guido. Curso de Direito Internacional Público. São Paulo: Atlas, 2002.

2003.

A proteção internacional do meio ambiente. Barueri-SP: Manole,

YOSHIDA, Consuelo Y M. Os Desafios à Implementação do Protocolo de Quioto: A Experiência e a Contribuição Japonesas e a Realidade Brasileira. Disponível em: <http://www.cori.rei.unicamp.br/BrasilJapao3/Trabalhos2005/ Trabalhos\%20 Completos/Protocolo\%20de\%20Kioto\%20Workshop.doc>. Acesso em: 21 fev. 2006. 